\title{
A review of child sexual abuse cases presenting to a paediatric emergency department
}

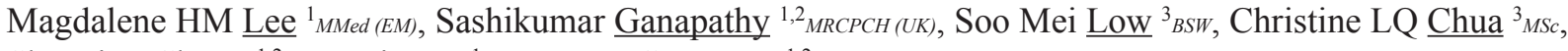
Shu-Ling Chong ${ }^{1,2}{ }_{M P H}$, Eric $\underline{\text { Ma }}{ }^{1}$ MBBS, Peter CY Wong ${ }^{1,2}$ MMed (Paeds)

\begin{abstract}
Introduction: Child sexual abuse (CSA) adversely affects a child's growth and well-being. This study aimed to describe the profile of children presenting to a tertiary paediatric emergency department (ED) with CSA.

Methods: Children 0-16 years old presenting to KK Women's and Children's Hospital ED from June 2016 to August 2020 with sexual abuse were retrospectively reviewed. We performed a secondary analysis on girls and stratified them by age $<13$ and $\geq 13$ years old.

Results: There were 790 patients who made 833 visits for CSA. Victims were predominantly girls $(747,94.8 \%)$ and perpetrators were predominantly men $(763,96.6 \%)$. The abuse first occurred before the age of 13 years in 315 victims (39.9\%). For 468 (59.2\%), more than one incident occurred before presentation. Compared to girls $\geq 13$ years old, girls $<13$ years old were more frequently abused by a family member $(47.7 \%$ versus $8.0 \%, P<0.001)$ and abused in their own home $(55.7 \%$ vs $21.0 \%$, $P<0.001)$. Among all children, parental divorce and the absence of one or both biological parents in the household were prevalent, with $287 / 783$ (36.7\%) having divorced parents, and only 374/784 $(47.8 \%)$ residing with both biological parents.

Conclusion: The findings highlight common characteristics of CSA cases, and can aid the future identification and protection of vulnerable children. The fact that most children presented after more than one incident suggests the need to more closely monitor and protect potentially at-risk children.
\end{abstract}

Ann Acad Med Singap 2021;50:527-35

Keywords: Child abuse, child sexual abuse, child welfare, sexual abuse

\section{INTRODUCTION}

Child sexual abuse (CSA) is a global public health issue with adverse short- and long-term repercussions. Formal definitions of CSA and the age for defining children differ around the world. In Singapore, CSA refers to any act where a child or young person below 16 years old is used for sexual pleasure or taken advantage of sexually. ${ }^{1}$

CSA has multiple consequences, many of which last into adulthood. Physical effects include sexually transmitted diseases such as human immunodeficiency virus infection ${ }^{2}$ and somatic complaints such as gastrointestinal disorders, chronic pain and psychogenic seizures. ${ }^{3}$ Many psychiatric consequences have been described, including post-traumatic stress disorder, sleep disorders, anxiety, depression, eating disorders, conversion disorder, borderline personality disorder, decreased self-esteem, decreased life satisfaction and suicide attempts. ${ }^{4-7}$ Behavioural outcomes include an increased risk of smoking, alcohol dependence, illicit drug use ${ }^{8}$ delinquency, criminal behaviour ${ }^{9}$ and risky sexual behaviour. ${ }^{10}$ There are suggestions of increased risks of future marital problems ${ }^{11}$ and dependence on welfare. ${ }^{7}$ Subsequent generations are also affected, with children of victims of CSA at greater risk of being born preterm, having a single mother, or being involved in protective services. ${ }^{12}$

In Singapore, the Child Protective Service (CPS) oversees the investigation of child abuse allegations and the protection of children. The number of CSA cases

\footnotetext{
${ }^{1}$ Department of Emergency Medicine, KK Women's and Children's Hospital, Singapore

${ }^{2}$ Duke-NUS Medical School, Singapore

${ }^{3}$ Medical Social Work Department, KK Women's and Children's Hospital, Singapore

Correspondence: Dr Magdalene HM Lee, Department of Emergency Medicine, KK Women's and Children's Hospital, 100 Bukit Timah Road, Singapore 229899.

Email: magdalene.lee2@mohh.com.sg
} 


\section{CLINICAL IMPACT}

\section{What is New}

- This is likely the first study describing the profile of child sexual abuse in Singapore.

- It is of great concern that girls $<13$ years old were frequently abused in their own home by a family member, and many children presented only after more than one incident of abuse had occurred.

- Girls <13 more often had parent- or familyrelated potential risk factors, while girls $\geq 13$ years old more often had psychiatric or behavioural issues.

\section{Clinical Implications}

- These findings can aid the future identification and protection of vulnerable children.

investigated by CPS increased from an average of 63.2 per year in 2010-2014 to an average of 165.6 per year in 2015-2019. ${ }^{13}$ A previous study described the profile of children hospitalised for child maltreatment, which included physical abuse, sexual abuse, emotional abuse and neglect. ${ }^{14}$ This study only included hospitalised children, whereas most children who present to the emergency department (ED) for sexual abuse are not admitted to hospital. Another study described the profile of children presenting to an ED for physical abuse only. ${ }^{15}$ There are no previous studies describing the profile of CSA cases in Singapore.

This study aimed to describe the profile of children 0-16 years old presenting with CSA to a paediatric ED in Singapore. With this information, we hope to aid future efforts to identify children potentially at risk of CSA and facilitate future development of preventive measures.

\section{METHODS}

We performed a retrospective chart review of electronic medical records. We included all patients aged 0-16 years old who presented to the ED of KK Women's and Children's Hospital (KKH) with sexual abuse from 17 June 2016 to 31 August 2020. KKH ED is the larger of 2 tertiary paediatric EDs in Singapore, and sees about 150,000 patients a year. The patients either presented of their own accord, with or without parents or guardians, for sexual abuse, or were accompanied by the police as part of the protocol for police investigations of CSA in Singapore, which includes a mandatory paediatric ED consultation for the purpose of safe disposition and referral to
Gynaecology. A referral to a multidisciplinary team, including a medical social worker (MSW), was subsequently made, either by the attending ED doctor if the patient was discharged, or by the inpatient team if the patient was admitted. For patients who presented more than once for CSA, only their first ED presentation was included.

Patients were identified using ED diagnosis codes of "sexual abuse", "child sexual abuse" and "sexual assault". The diagnosis code of "child abuse" was also screened but did not yield any CSA cases. Data were extracted from ED records, follow-up outpatient specialist clinic records and MSW records. A structured data extraction form was used to extract information on the child's demographics, details of the sexual abuse, perpetrator characteristics, the presence of pregnancy or sexually transmitted infections, the child's background (e.g. psychiatric or behavioural issues, substance use, previous encounters with social service agencies), the child's family structure, and potential associated family characteristics (e.g. history of parental incarceration or illicit drug use). Each case was assigned a unique case identifier, and patient identifiers were not entered into the dataset. Our definition of CSA, and thus our study population, included cases where the victim was aged below 16 years, the legal age of consent for sexual activity, and voluntarily participated in the sexual activity. In our study, we referred to these cases of voluntary participation as "consensual" as opposed to "nonconsensual".

We described categorical data using frequencies and percentages, and continuous data using mean and standard deviation (SD). We performed a secondary analysis on girls, stratifying them by age $<13$ and $\geq 13$ years, and compared the 2 groups for differences in abuse characteristics and risk factors. Boys were not included in this analysis due to their small number in the study, and characteristics between female and male victims of CSA are known to be different. ${ }^{16}$ We differentiated between these 2 age groups because children typically progress from primary to secondary school education at age 13 and may have an associated increase in autonomy. Categorical variables were analysed using chi-square tests and continuous variables were analysed using Student's t-test. Data were analysed using SPSS Statistics software version 23 (IBM Corp, Armonk, US).

The study was approved by the SingHealth Centralised Institutional Review Board (2020/2761). The requirement for informed consent was waived due to the minimal risks of the study, the low feasibility 
of retrospectively obtaining consent from a large number of patients, and the risk of inflicting psychological damage on patients by contacting them regarding a potentially traumatic past event.

\section{RESULTS}

\section{Epidemiology}

There were 790 patients who made 833 visits to the ED for CSA. Of these, 38 patients presented more than once for CSA, and only their first visit was included in the study. From 2016 to 2019, a mean of 16.2 patients per month were seen (Table 1). Fewer patients were seen in 2020 (mean of 13.0 per month) due to a fall in attendances by about half from April to July 2020, compared to the same period in the preceding years. This coincided with COVID-19 movement restrictions imposed nation-wide from 2 April to 1 June 2020, and subsequent phased reopening measures. The majority $(747,94.6 \%)$ of patients were girls, and $261(33.0 \%)$ patients presented at $<13$ years old. Ethnic distribution is as shown in Table 1.

\section{Abuse characteristics}

Abuse characteristics are described in Table 2. The first abuse occurred at $<13$ years old for $315(39.9 \%)$ of patients. The majority $(468,59.2 \%)$ had more than one alleged event of CSA prior to presentation. The perpetrators were predominantly male for both female $(721 / 747,96.5 \%)$ and male $(42 / 43,97.7 \%)$ victims. A small proportion of victims was subjected to concurrent physical abuse $(19,2.4 \%)$.
The abuse involved non-consensual acts in 432 victims $(54.7 \%)$. The abuse was non-consensual for most male victims $(36 / 43,83.7 \%)$, and for more than half of female victims (396/747, 53.0\%). Among girls $<13$ years old compared to those $\geq 13$ years old, the abuse was more frequently non-consensual (210/237, 88.6\% versus 186/510, 36.5\%, $P<0.001)$ and intrafamilial $(113,47.7 \%$ vs $41,8.0 \%, P<0.001)$. In contrast, the perpetrator was most commonly a friend $(452,88.6 \%)$ for girls $\geq 13$ years old. For girls $<13$ years old, the perpetrator more frequently lived in the same household $(116,48.9 \%$ vs $34,6.7 \%$, $P<0.001$ ), and the perpetrators were generally older (mean 30.5, SD 15.7 vs mean 19.1, SD 8.4, $P<0.001$ ). For girls $<13$ years old, the abuse occurred most frequently in the patient's residence $(132,55.7 \%$, $P<0.001$ ), whereas for girls $\geq 13$ years old, the abuse occurred most commonly in the perpetrator's residence $(205,40.2 \%)$, followed by the patient's residence $(107,21.0 \%)$.

Girls $\geq 13$ years old were more likely to have been involved in more intrusive abuses, with higher rates of penile-vaginal intercourse $(390,76.5 \%$ vs $56,23.6 \%$, $P<0.001)$ and penile-oral or oral-vaginal intercourse $(15.4,30.2 \%$ vs $38,16.0 \%, P<0.001)$. In contrast, girls $<13$ years old were more likely to have been fondled with no penetration $(88,37.1 \%$ vs $18,3.5 \%, P<0.001)$.

\section{Disclosure}

Eight children were preverbal. Of the 782 children who could communicate verbally, 454/740 (61.4\%) had

Table 1. Year-on-year demographics between 2016 and 2020

\begin{tabular}{|c|c|c|c|c|c|c|}
\hline Year & $2016^{a}$ & 2017 & 2018 & 2019 & $2020^{b}$ & Total \\
\hline Total no. of cases & 115 & 185 & 189 & 197 & 104 & 790 \\
\hline Mean no. of cases per month & 17.8 & 15.4 & 15.8 & 16.4 & 13.0 & 15.7 \\
\hline Girls, no. $(\%)$ & $100(87.0)$ & $174(94.1)$ & $179(94.7)$ & $194(98.5)$ & $100(96.2)$ & $747(94.6)$ \\
\hline Age < 13 , no. $(\%)$ & $45(39.1)$ & $73(39.5)$ & $64(33.9)$ & $60(30.5)$ & $19(18.3)$ & $261(33.0)$ \\
\hline Girls aged $<13$, no. $(\%)^{\mathrm{c}}$ & $37(37.0)$ & $67(38.5)$ & $59(33.0)$ & $58(29.9)$ & $16(16.0)$ & $237(31.7)$ \\
\hline \multicolumn{7}{|l|}{ Ethnicity, no. (\%) } \\
\hline Chinese & $55(47.8)$ & $88(47.6)$ & $82(43.4)$ & $92(46.7)$ & $45(43.3)$ & $362(45.8)$ \\
\hline Malay & $37(32.2)$ & $75(40.5)$ & $75(39.7)$ & $82(41.6)$ & $51(49.0)$ & $320(40.5)$ \\
\hline Indian & $15(13.0)$ & $13(7.0)$ & $23(12.2)$ & $13(6.6)$ & $2(1.9)$ & $66(8.4)$ \\
\hline
\end{tabular}

a From 17 June 2016 to 31 December 2016 (6.47 months)

${ }^{\mathrm{b}}$ From 1 January 2020 to 31 August 2020 (8 months)

${ }^{\mathrm{c}}$ Percentage out of number of girls presenting in that year 
Table 2. Abuse characteristics

\begin{tabular}{|c|c|c|c|c|c|}
\hline \multirow[t]{2}{*}{ Characteristic } & \multirow[t]{2}{*}{ Total $(\mathrm{N}=790)$} & \multicolumn{4}{|c|}{ Girls } \\
\hline & & All $(n=747)$ & $<13(n=237)$ & $\geq 13(n=510)$ & $P$ value ${ }^{a}$ \\
\hline Age $<13$ at first incident, no. (\%) & 315 (39.9) & $289(38.7)$ & - & - & - \\
\hline$>1$ incident of sexual abuse prior to presentation, no. $(\%)$ & $468(59.2)$ & $445(59.6)$ & $129(54.4)$ & $316(62.0)$ & 0.051 \\
\hline Non-consensual, no. (\%) & $432(54.7)$ & $396(53.0)$ & $210(88.6)$ & $186(36.5)$ & $<0.001$ \\
\hline Perpetrator male, no. (\%) & $763(96.6)$ & $721(96.5)$ & $214(90.3)$ & $507(99.4)$ & $<0.001$ \\
\hline Perpetrator age (mean $\pm \mathrm{SD})$ & $23.3 \pm 12.9$ & $22.7 \pm 12.4$ & $30.5 \pm 15.7$ & $19.1 \pm 8.4$ & $<0.001$ \\
\hline Intrafamilial, no. (\%) & $171(21.6)$ & $154(20.6)$ & $113(47.7)$ & $41(8.0)$ & $<0.001$ \\
\hline \multicolumn{6}{|l|}{ Relationship of perpetrator to child, no. (\%) } \\
\hline Friend & $524(66.3)$ & $510(68.3)$ & $58(24.5)$ & $452(88.6)$ & - \\
\hline Mother's partner & $34(4.3)$ & $34(4.6)$ & $19(8.0)$ & $15(2.9)$ & - \\
\hline Other relative & $60(7.6)$ & $52(7.0)$ & $41(17.3)$ & $11(2.2)$ & - \\
\hline Helper & $16(2.0)$ & $15(2.0)$ & $15(6.3)$ & $0(0.0)$ & - \\
\hline Teacher & $16(2.0)$ & $14(1.9)$ & $11(4.6)$ & $3(0.6)$ & - \\
\hline Others & $63(8.0)$ & $54(7.2)$ & $40(16.9)$ & $14(2.7)$ & - \\
\hline Perpetrator in same household as child, no. (\%) & $171(21.6)$ & $150(20.1)$ & $116(48.9)$ & $34(6.7)$ & $<0.001$ \\
\hline Location of most recent incident, no. (\%) & & & & & $<0.001$ \\
\hline Patient's residence & $260(32.9)$ & $239(32.0)$ & $132(55.7)$ & $107(21.0)$ & \\
\hline Perpetrator's residence & $244(30.9)$ & $236(31.6)$ & $31(13.1)$ & $205(40.2)$ & \\
\hline Others & $186(23.5)$ & $172(23.0)$ & $54(22.8)$ & $118(23.1)$ & \\
\hline \multicolumn{6}{|l|}{ Type of sexual abuse, no. (\%) } \\
\hline Penile-vaginal & $446(56.5)$ & $446(59.7)$ & $56(23.6)$ & $390(76.5)$ & $<0.001$ \\
\hline Penile-oral/Oral-vaginal & $206(26.1)$ & $192(25.7)$ & $38(16.0)$ & $154(30.2)$ & $<0.001$ \\
\hline Digital penetration & $303(38.4)$ & $296(39.6)$ & $98(41.4)$ & $198(38.8)$ & 0.511 \\
\hline Penile-anal & $50(6.3)$ & $32(4.3)$ & $8(3.4)$ & $24(4.7)$ & 0.403 \\
\hline Foreign object penetration & $13(1.6)$ & $10(1.3)$ & $9(3.8)$ & $1(0.2)$ & $<0.001$ \\
\hline Fondling with no penetration & $118(14.9)$ & $106(14.2)$ & $88(37.1)$ & $18(3.5)$ & $<0.001$ \\
\hline Voluntary disclosure, no. $(\%)^{\mathrm{b}}$ & $490 / 782(62.7)$ & $454 / 740(61.4)$ & $188 / 230(81.7)$ & $266 / 510(52.2)$ & $<0.001$ \\
\hline \multicolumn{6}{|l|}{ If voluntarily disclosed, person to whom child disclosed, no. (\%) } \\
\hline Parent/Guardian & $220 / 490(44.9)$ & $201 / 454(44.3)$ & 129/188 (68.6) & $72 / 266(27.1)$ & - \\
\hline Other relative & $34 / 490(6.9)$ & $34 / 454(7.5)$ & $17 / 188(9.0)$ & $17 / 266(6.4)$ & - \\
\hline Teacher/Counsellor/Youth worker & $125 / 490(25.5)$ & $112 / 454(24.7)$ & 25/188 (13.3) & $87 / 266(32.7)$ & - \\
\hline Friend & $60 / 490(12.2)$ & $59 / 454(13.0)$ & $8 / 188(4.3)$ & $51 / 266(19.2)$ & - \\
\hline Other & $51 / 490(10.4)$ & 48/454 (10.6) & $9 / 188(4.8)$ & $39 / 266(14.7)$ & - \\
\hline
\end{tabular}

${ }^{\text {a }}$ Comparing girls aged $<13$ and $\geq 13$

${ }^{\mathrm{b}}$ Not including preverbal children 
voluntarily disclosed the abuse to another person prior to presentation. Girls $<13$ years old more often voluntarily disclosed compared to girls $\geq 13$ years old $(188 / 230,81.7 \%$ vs $266 / 510,52.2 \%, P<0.001)$. Among those who voluntarily disclosed, girls $<13$ years old most commonly disclosed to parents or guardians $(129 / 188,68.6 \%)$, whereas girls $\geq 13$ years old disclosed to teachers, counsellors or youth workers $(87 / 266,32.7 \%)$, parents or guardians $(72,27.1 \%)$, or friends $(51,19.2 \%)$. Those who had not voluntarily disclosed were typically brought to medical attention because of suspicions on the part of parents or other adults.

When comparing consensual and non-consensual acts, children involved in non-consensual acts were significantly more likely to voluntarily disclose the abuse $(350 / 422,82.9 \%$ vs $140 / 358,39.1 \%, P<0.001)$, and were more likely to disclose the abuse to parents or guardians $(183 / 350,52.3 \%$ vs $37 / 140,26.4 \%$, $P<0.001$ ). On subgroup analysis of girls $\geq 13$ years old, a similar pattern of voluntary disclosure (nonconsensual $140 / 184,76.1 \%$ vs consensual $126 / 324$, $38.9 \%, P<0.001)$ was observed. However, in this subgroup, there was no significant difference in rates of disclosure to parents or guardians between those involved in non-consensual and consensual acts (40/140, $28.6 \%$ vs $32 / 126,25.4 \%, P=0.561)$.

\section{Consequences}

Table 3 shows consequences resulting from sexual abuse. Girls $<13$ years old were more likely to be admitted to hospital compared to those $\geq 13$ years old $(42,17.7 \%$ vs $25,4.9 \%, P<0.001)$. This was likely for child protection reasons, given the higher rates of intrafamilial sexual abuse in the younger age group.

\section{Psychiatric, behavioural and familial characteristics}

Psychiatric, behavioural and familial characteristics for CSA are shown in Table 4. Just over half of the patients had parents who were married to each other $(411 / 783,52.5 \%)$. The others had parents who were divorced, never married, or deceased. Less than half $(374 / 784,47.7 \%)$ lived in the same home as both biological parents. The majority lived with a single parent (including cases where the other parent was incarcerated), step-parent, other relative, or in a foster home or institution.

Among girls, those $<13$ years old more commonly had parent- or family-related potential risk factors, such as a parental history of illicit drug use (19/201, $9.5 \%$ vs $21 / 461,4.6 \%, P=0.015$ ) or a parental history of incarceration $(28 / 233,12.0 \%$ vs $28 / 498,5.6 \%$, $P=0.002)$. In contrast, those $\geq 13$ years old more commonly had child-related potential risk factors, such as a history of psychiatric or behavioural issues $(230 / 510,45.1 \%$ vs $27 / 237,11.4 \%, P<0.001)$, a history of smoking $(161 / 347,46.4 \%$ vs $15 / 211,7.1 \%$, $P<0.001)$, a history of alcohol use $(75 / 333,22.5 \%$ vs $6 / 209,2.9 \%, P<0.001$ ) or a history of illicit drug use $(23 / 333,6.9 \%$ vs $2 / 209,1.0 \%, P=0.001)$.

Three in $8(294 / 790,37.2 \%)$ patients were previously known to CPS, a MSW, a counsellor, or other social service organisations. One in $8(98 / 790,12.4 \%)$ had either a previous ED visit or hospital admission for maltreatment, or a subsequent one during the study period.

\section{DISCUSSION}

Our study showed that CSA is a major problem in Singapore, with $39.9 \%$ of the victims in our study having been abused before they were 13 years old.

Table 3. Consequences of sexual abuse

\begin{tabular}{|c|c|c|c|c|c|}
\hline \multirow[t]{2}{*}{ Consequence } & \multirow[t]{2}{*}{ Total $(\mathrm{N}=790)$} & \multicolumn{4}{|c|}{ Girls } \\
\hline & & All $(n=747)$ & $<13(n=237)$ & $\geq 13(n=510)$ & $P$ value ${ }^{a}$ \\
\hline Pregnant, no. (\%) & - & $39(5.2)$ & $1(0.4)$ & $38(7.5)$ & $<0.001$ \\
\hline Sexually transmitted infections, no. (\%) & $49(6.2)$ & $47(6.3)$ & $4(1.7)$ & $43(8.4)$ & $<0.001$ \\
\hline Gonorrhoea & $7(0.9)$ & $6(0.8)$ & $1(0.4)$ & $5(1.0)$ & 0.426 \\
\hline Chlamydia & $44(5.6)$ & $43(5.8)$ & $3(1.3)$ & $40(7.8)$ & $<0.001$ \\
\hline Pelvic inflammatory disease & $1(0.1)$ & $1(0.1)$ & $0(0.0)$ & $1(0.2)$ & 0.495 \\
\hline Presence of injuries, no. (\%) & $34(4.3)$ & $30(4.0)$ & $21(8.9)$ & $9(1.8)$ & $<0.001$ \\
\hline Admitted to hospital, no. (\%) & $82(10.4)$ & $67(9.0)$ & $42(17.7)$ & $25(4.9)$ & $<0.001$ \\
\hline
\end{tabular}

${ }^{a}$ Comparing girls aged $<13$ and $\geq 13$ 
Table 4. Psychiatric, behavioural and familial characteristics

\begin{tabular}{|c|c|c|c|c|c|}
\hline \multirow[t]{2}{*}{ Characteristic } & \multirow[t]{2}{*}{ Total } & \multicolumn{4}{|c|}{ Girls } \\
\hline & & All & $<13$ & $\geq 13$ & $P$ value ${ }^{a}$ \\
\hline \multicolumn{6}{|l|}{ Child-related characteristics } \\
\hline History of psychiatric or behavioural issues, no. (\%) & $265 / 790(33.5)$ & $257 / 747(34.4)$ & 27/237 (11.4) & $230 / 510(45.1)$ & $<0.001$ \\
\hline Special needs/Developmental delay, no. (\%) & $53 / 790(6.7)$ & $45 / 747(6.0)$ & $22 / 237(9.3)$ & $23 / 510(4.5)$ & 0.011 \\
\hline History of smoking, no. $(\%)$ & $181 / 586(30.9)$ & $176 / 558(31.5)$ & $15 / 211(7.1)$ & $161 / 347(46.4)$ & $<0.001$ \\
\hline History of alcohol use, no. (\%) & $82 / 569(14.4)$ & $81 / 542(14.9)$ & $6 / 209(2.9)$ & $75 / 333(22.5)$ & $<0.001$ \\
\hline History of illicit drug use, no. (\%) & $26 / 569(4.6)$ & $25 / 542(4.6)$ & $2 / 209(1.0)$ & $23 / 333(6.9)$ & 0.001 \\
\hline History of institutionalisation, no. (\%) & $57 / 790(7.2)$ & $53 / 747(7.1)$ & $11 / 237(4.6)$ & $42 / 510(8.2)$ & 0.075 \\
\hline Previously known to social services, no. (\%) & $294 / 790(37.2)$ & 276/747 (36.9) & $65 / 237(27.4)$ & $211 / 510(41.4)$ & $<0.001$ \\
\hline Medical social worker, no. (\%) & $122 / 790(15.4)$ & $115 / 747(15.4)$ & $38 / 237(16.0)$ & $77 / 510(15.1)$ & 0.742 \\
\hline Counsellor/Others, no. (\%) & $266 / 790(33.7)$ & $251 / 747(33.6)$ & $54 / 237(22.8)$ & $197 / 510(38.6)$ & $<0.001$ \\
\hline \multicolumn{6}{|l|}{ Parent- or family-related characteristics } \\
\hline \multicolumn{6}{|l|}{ Marital status of parents, no. $(\%)^{b}$} \\
\hline Married & $411 / 783(52.5)$ & $384 / 741(51.8)$ & $118 / 236(50.0)$ & $266 / 505(52.7)$ & 0.497 \\
\hline Divorced & $287 / 783(36.7)$ & $275 / 741(37.1)$ & $101 / 236(42.8)$ & $174 / 505(34.5)$ & - \\
\hline Never married & $52 / 783(6.6)$ & 49/741 (6.6) & $10 / 236(4.2)$ & $39 / 505(7.7)$ & - \\
\hline One or both deceased & $33 / 783(4.2)$ & $33 / 741(4.5)$ & $7 / 236(3.0)$ & $26 / 505(5.1)$ & - \\
\hline \multicolumn{6}{|l|}{ Child living with, no. (\%) } \\
\hline Single biological parent & $114 / 784(14.5)$ & 108/741 (14.6) & $42 / 236(17.8)$ & $66 / 505(13.1)$ & - \\
\hline Biological parent + Step-parent & $118 / 784(15.1)$ & $113 / 741(15.2)$ & 28/236 (11.9) & $85 / 505(16.8)$ & - \\
\hline Biological parent + Other relative & $64 / 784(8.2)$ & $59 / 741(8.0)$ & 28/236 (11.9) & $31 / 505(6.1)$ & - \\
\hline Other relative & $50 / 784(6.4)$ & $48 / 741(6.5)$ & $14 / 236(5.9)$ & $34 / 505(6.7)$ & - \\
\hline Non-relative, e.g. adopted or foster parent & 23/784 (2.9) & $23 / 741(3.1)$ & $7 / 236(3.0)$ & $16 / 505(3.2)$ & - \\
\hline Institutionalised & $41 / 784(5.2)$ & $38 / 741(5.1)$ & $9 / 236(3.8)$ & $29 / 505(5.7)$ & - \\
\hline Mother employed, no. (\%) & $518 / 769(67.4)$ & $495 / 729(67.9)$ & $160 / 232(69.0)$ & $335 / 497(67.4)$ & 0.674 \\
\hline History of illicit drug use in parents, no. (\%) & $46 / 699(6.6)$ & $40 / 662(6.0)$ & $19 / 201(9.5)$ & $21 / 461(4.6)$ & 0.015 \\
\hline History of incarceration of parents, no. (\%) & $60 / 769(7.8)$ & $56 / 731(7.7)$ & $28 / 233(12.0)$ & $28 / 498(5.6)$ & 0.002 \\
\hline History of domestic violence in family, no. (\%) & $109 / 774(14.1)$ & $103 / 734(14.0)$ & $43 / 234(18.4)$ & $60 / 500(12.0)$ & 0.020 \\
\hline
\end{tabular}

a Comparing girls aged $<13$ and $\geq 13$

${ }^{\mathrm{b}}$ The discrepancy between 783 and 784 is due to missing data of 1 child about the marital status of the parents.

Similar to worldwide studies, ${ }^{16-18}$ most of the victims were girls and most of the perpetrators were men. However, the proportion of victims who were boys $(43,5.4 \%)$ in our study was lower than global reports, ${ }^{16,17}$ even in comparison to other Asian countries such as South Korea, ${ }^{19}$ China $^{20}$ and Taiwan. ${ }^{21}$ There are reports that boys are more reluctant to disclose CSA. $^{22-24}$ Reasons that have been postulated include boys fearing not being recognised as a victim, being perceived as less masculine, or being labelled 
homosexual. ${ }^{22,25}$ It is unclear whether the low proportion of boys in our study is due to a true lower prevalence or a lower rate of disclosure.

The Singapore ethnic composition in 2020 was $74.3 \%$ Chinese, $13.5 \%$ Malay, 9.0\% Indian and 3.2\% others. ${ }^{26}$ Comparing the ethnic composition of victims to national statistics, there were proportionately fewer Chinese $(362,45.8 \%)$ and more Malay (320, 40.5\%) victims. Further research is needed to understand the reasons for the ethnic distribution of patients who presented to the ED, and the extent to which this distribution reflects differences in the prevalence and disclosure rates of CSA between ethnic groups.

Certain differences in characteristics of the abuse between girls aged $<13$ and $\geq 13$ years old were similar to differences found in studies conducted in other countries. Those aged $<13$ years old were more likely to be involved in non-consensual and intrafamilial abuses, whereas those aged $\geq 13$ years old were more likely to be involved in consensual and extrafamilial underaged sexual activity. This was similar to previous studies that showed that younger children are more likely to be victimised by a parent or relative, whereas older children are more likely to be victimised by extrafamilial perpetrators. ${ }^{27-29}$ Those $\geq 13$ years old were also more likely to have penetrative abuse, especially penile-vaginal and penile-anal penetration, which was consistent with previous findings. ${ }^{27}$

Interestingly, potential risk factors were different for girls aged $<13$ and $\geq 13$ years old. Previous studies have demonstrated that risk factors for CSA can be grouped into child-, parent- and family-related domains. ${ }^{30}$ In our study, we found that child-related potential risk factors such as a history of psychiatric or behavioural issues, smoking, alcohol use and illicit drug use were more common in the $\geq 13$ age group, whereas parent- and family-related potential risk factors such as a parental history of illicit drug use or incarceration were more common in the $<13$ age group. It should be noted that child behavioural issues such as smoking, alcohol use and illicit drug use are generally more common in the $\geq 13$ age group, and it was not within the scope of our study to conclude whether they were more common in CSA victims than in the general paediatric population. The interplay of factors contributing to CSA is complex and causality relationships may be difficult to determine. However, the differing characteristics between the $<13$ and $\geq 13$ age groups indicate that existing strategies to identify and prevent CSA could be specifically targeted at different age groups. For example, we suggest that for at-risk families with younger children, schools, prisons, courts, hospitals and community agencies could work more closely with individuals or family groups to identify possible threats to child safety, including those created by prolonged parental absence resulting from parental divorce or incarceration. For teenagers in whom curiosity and peer influence may contribute to risktaking behaviours, more emphasis could be placed on equipping parents and teachers to handle issues relating to teenage sexuality and to educate teenagers on managing situations that may lead to sexual abuse.

In children of both sexes and age groups, parental divorce was prevalent. The parental divorce rate of $36.7 \%$ in the study is in contrast to national statistics that show $21.1 \%$ of marriages are dissolved by the 15 th year of marriage. ${ }^{31}$ The majority of children lived in a household that did not include both biological parents. It is reported that children from non-nuclear families are at higher risk for CSA victimisation, ${ }^{30,32}$ and they form an important group for schools, courts and social service agencies to target in efforts to detect and reduce CSA.

While the majority of children voluntarily disclosed the abuse, this was more common among girls $<13$ compared to those $\geq 13$ years old. Moreover, while most girls $<13$ years old disclosed to their parents or guardians, those $\geq 13$ years old disclosed to a wider variety of people including teachers, counsellors, youth workers and friends, with only a quarter disclosing to their parents or guardians. In addition, although those involved in non-consensual acts, compared to those involved in consensual acts, were more likely to disclose to parents or guardians, this difference was not seen when analysing girls $\geq 13$ years old. This was consistent with previous studies that have found that adolescents are less likely to disclose to parents compared to younger children. ${ }^{27}$ It has been proposed that this may be because adolescents may feel that family members will react more negatively to a disclosure, especially when the perpetrator is known to the family. ${ }^{33}$

We found a worrying trend that the majority of children experienced recurring incidents of CSA before presenting to the ED, suggesting a delay in disclosure. Previous studies exploring why children may be reluctant to disclose CSA have found that barriers to disclosure include emotions of guilt and shame, not considering themselves to be abused, a perceived lack of understanding and limited support from adults, the fear of parental sanctions, and the fear of negative consequences for the offender and the child's own family. ${ }^{34-36}$ Further investigations need to be carried out to identify barriers to disclosure in 
Singapore's cultural context. We believe that efforts should be taken to encourage prompt disclosure before recurrent events occur. This could include training parents and teachers on effective questioning of children about possible $\mathrm{CSA},{ }^{35}$ providing more opportunities for children to disclose, and providing avenues for friends of victims, particularly adolescent victims, to disclose. . $^{33,37}$

It is notable that $37.2 \%$ of the children were previously known to social services prior to their ED visit. In Singapore, the child protection system involves statutory interventions via CPS, specialised community-based interventions via child protection specialist centres, and community-based services via community agencies such as family service centres and school-based services ${ }^{38}$. These offer a wide range of targeted services at the legal, educational, community and healthcare levels. In the acute hospital setting, CSA cases are referred to MSWs, and the type of support offered depends on the patient's age and whether the event was consensual. For children aged $\geq 13$ years who engage in consensual acts, MSWs typically offer education on sexuality, handling peer relationships and contraception. For children of all ages involved in non-consensual acts, MSWs typically focus on screening for trauma symptoms, providing emotional support and counselling, and educating children on recognising and avoiding potentially dangerous situations.

The occurrence of CSA in the group of children already known to social services suggests that more can be done for primary and secondary prevention of CSA. For young children, previous research has found that education programmes are more effective when based on concrete concepts, such as appropriate touch and what is forbidden, rather than abstract concepts such as rights and feelings. ${ }^{39}$ We suggest that schools and community organisations work together with parents and caregivers to equip young children with the knowledge of recognising inappropriate sexual behaviour and developing preventive skills. For teenagers, there is evidence that programmes that increase attachment to school or reduce school dropout are effective in delaying sexual activity and reducing teenage pregnancy, even when the programmes do not directly address sexuality. Besides providing sexual education, schools offer opportunities for youths to succeed, and help them to develop plans for higher education and careers. ${ }^{40}$ We suggest that programmes focus on keeping teenagers engaged in schools, including giving pregnant youths the opportunity to continue their studies.
The study was limited by its retrospective nature. There may be inaccuracies in self-reported data obtained from interviews with children and their caregivers, especially regarding sensitive information such as the children's history of substance use and their parents' history of illicit drug use or incarceration. The history was also limited in young, and especially preverbal, children. In addition, we were only able to include cases that were brought to medical attention, and were unable to account for cases that were unreported. In particular, the low proportion of boys in our study suggests the possibility of under-reporting of male victims. The fall in reported cases in 2020 during the period of national COVID-19 movement restrictions also suggests that the true rate of CSA may have been under-represented during this period. The characteristics of unreported cases may differ from reported cases, and further studies are required to investigate the prevalence of under-reporting of CSA in Singapore and the nature of unreported cases. Finally, we were unable to determine if families utilised community resources and sought help through existing helplines prior to or after the ED attendance. We were therefore unable to fully evaluate the utility and effectiveness of existing community resources.

\section{CONCLUSION}

Our study highlights that CSA is an important problem in Singapore and found that girls $<13$ years old were frequently abused in their own home by a family member. Parental divorce and not living with both biological parents were frequent in the population. Girls $\geq 13$ years old more frequently had psychiatric and behavioural issues, and a history of smoking and/or alcohol use. Understanding the characteristics associated with CSA will enable vulnerable groups of children to be identified and protected, for example by training them to recognise and avoid situations that may lead to sexual abuse. We found that many children presented after more than one incident of abuse, suggesting that potentially at-risk children require closer surveillance by parents, schools and support organisations, and that they should be provided with more opportunities for disclosure.

\section{REFERENCES}

1. Singapore Statutes Online. Child and Young Persons Act. Sect. 7, 31 December 2001. Available at: https://sso.agc.gov.sg/Act/ CYPA1993\#pr7-. Accessed on 29 November 2020.

2. Bechtel K. Sexual abuse and sexually transmitted infections in children and adolescents. Curr Opin Pediatr 2010;22:94-9. 
3. Paras ML, Murad MH, Chen LP, et al. Sexual abuse and lifetime diagnosis of somatic disorders: a systematic review and metaanalysis. JAMA 2009;302:550-61.

4. Chen LP, Murad MH, Paras ML, et al. Sexual Abuse and Lifetime Diagnosis of Psychiatric Disorders: Systematic Review and Metaanalysis. Mayo Clin Proc 2010;85:618-29.

5. Ng QX, Yong BZJ, Ho CYX, et al. Early life sexual abuse is associated with increased suicide attempts: An update metaanalysis. J Psychiatr Res 2018;99:129-41.

6. Hailes HP, Yu R, Danese A, et al. Long-term outcomes of childhood sexual abuse: an umbrella review. Lancet Psychiatry 2019;6:830-9.

7. Fergusson DM, McLeod GFH, Horwood LJ. Childhood sexual abuse and adult developmental outcomes: findings from a 30-year longitudinal study in New Zealand. Child Abuse Negl 2013;37:664-74.

8. Nelson EC, Heath AC, Lynskey MT, et al. Childhood sexual abuse and risks for licit and illicit drug-related outcomes: a twin study. Psychol Med 2006;36:1473-3.

9. Herrera VM, McCloskey LA. Sexual abuse, family violence, and female delinquency: findings from a longitudinal study. Violence Vict 2003;18:319-34.

10. van Roode $\mathrm{T}$, Dickson N, Herbison $\mathrm{P}$, et al. Child sexual abuse and persistence of risky sexual behaviors and negative sexual outcomes over adulthood: findings from a birth cohort. Child Abuse Negl 2009;33:161-72.

11. Dube SR, Anda RF, Whitfield CL, et al. Long-term consequences of childhood sexual abuse by gender of victim. Am J Prev Med 2005;28:430-8.

12. Noll JG, Trickett PK, Harris WW, et al. The cumulative burden borne by offspring whose mothers were sexually abused as children: descriptive results from a multigenerational study. J Interpers Violence 2009;24:424-49.

13. Ministry of Social and Family Development. Child Abuse Investigations, 16 April 2020. Available at: https:/www.msf.gov. $\mathrm{sg} /$ research-and-data/Research-and-Statistics/Pages/Child-AbuseInvestigations.aspx. Accessed on 29 November 2020.

14. Ngiam XY, Kang YQ, Aishworiya R, et al. Child maltreatment syndrome: demographics and developmental issues of inpatient cases. Singapore Med J 2015;56:612-7.

15. Chew YR, Cheng MH, Goh MC, et al. Five-Year Review of Patients Presenting with Non-Accidental Injury to a Children's Emergency Unit in Singapore. Ann Acad Med Singap 2018;47:413-9.

16. Stoltenborgh M, van Ijzendoorn MH, Euser EM, et al. A global perspective on child sexual abuse: meta-analysis of prevalence around the world. Child Maltreat 2011;16:79-101

17. Barth J, Bermetz L, Heim E, et al. The current prevalence of child sexual abuse worldwide: a systematic review and meta-analysis. Int J Public Health 2013;58:469-83

18. Murray LK, Nguyen A, Cohen JA. Child sexual abuse. Child Adolesc Psychiatr Clin N Am 2014;23:321-37.

19. Lee Y, Kim S. Childhood maltreatment in South Korea: retrospective study. Child Abuse Negl 2011;35:1037-44

20. Ma Y. Prevalence of Childhood Sexual Abuse in China: A Meta-Analysis. J Child Sex Abus 2018;27:107-21.

21. Chen CT, Yang NP, Chou P. Child maltreatment in Taiwan for 2004-2013: A shift in age group and forms of maltreatment. Child Abuse Negl 2016;52:169-76.
22. Gagnier C, Collin-Vézina D. The Disclosure Experiences of Male Child Sexual Abuse Survivors. J Child Sex Abus 2016; 25:221-41.

23. O'Leary PJ, Barber J. Gender differences in silencing following childhood sexual abuse. J Child Sex Abus 2008;17:133-43.

24. Lev-Wiesel R, First M. Willingness to disclose child maltreatment: CSA vs other forms of child abuse in relation to gender. Child Abuse Negl 2018;79:183-91.

25. Sivagurunathan M, Orchard T, MacDermid JC, et al. Barriers and facilitators affecting self-disclosure among male survivors of child sexual abuse: The service providers' perspective. Child Abuse Negl 2019;88:455-65.

26. Singapore Department of Statistics. Population Trends 2020, September 2020. Available at: https://www.singstat.gov.sg/-/media/ files/publications/population/population2020.pdf. Accessed on 14 December 2020.

27. Giroux ME, Chong K, Coburn PI, et al. Differences in child sexual abuse cases involving child versus adolescent complainants. Child Abuse Negl 2018;79:224-33.

28. Ho TP, Mak FL. Sexual abuse in Chinese children in Hong Kong: a review of 134 cases. Aust N Z J Psychiatry 1992;26:639-43.

29. Fischer DG, McDonald WL. Characteristics of intrafamilial and extrafamilial child sexual abuse. Child Abuse Negl 1998;22:915-29.

30. Assink M, van der Put CE, Meeuwsen MWCM, et al. Risk factors for child sexual abuse victimization: A meta-analytic review. Psychol Bull 2019;145:459-89.

31. Ministry of Social and Family Development. Dissolution of Marriages Among Marriage Cohorts, 1987-2015, 2018. Available at: https:/www.msf.gov.sg/research-and-data/Research-and-Statistics/ Documents/Statistics\%20Series\%20-\%20Dissolution\%20of\%20 Marriages\%201987-2015.pdf. Accessed on 14 December 2020.

32. Finkelhor D, Moore D, Hamby SL, et al. Sexually abused children in a national survey of parents: methodological issues. Child Abuse Negl 1997;21:1-9.

33. Kogan SM. Disclosing unwanted sexual experiences: results from a national sample of adolescent women. Child Abuse Negl 2004; 28:147-65.

34. Lemaigre C, Taylor EP, Gittoes C. Barriers and facilitators to disclosing sexual abuse in childhood and adolescence: A systematic review. Child Abuse Negl 2017;70:39-52.

35. Morrison SE, Bruce C, Wilson S. Children's Disclosure of Sexual Abuse: A Systematic Review of Qualitative Research Exploring Barriers and Facilitators. J Child Sex Abus 2018;27:176-94.

36. Paine ML, Hansen DJ. Factors influencing children to self-disclose sexual abuse. Clin Psychol Rev 2002;22:271-95.

37. Priebe G, Svedin CG. Child sexual abuse is largely hidden from the adult society. An epidemiological study of adolescents' disclosures. Child Abuse Negl 2008;32:1095-108.

38. Ministry of Social and Family Development. Protecting the Safety and Well-Being of Children, 2016. Available at: https:/www.msf.gov. $\mathrm{sg} /$ policies/Strong-and-Stable-Families/Nurturing-and-Protectingthe-Young/Child-Protection-Welfare/Pages/Protecting-Children.aspx. Accessed on 13 May 2021.

39. Collin-Vézina D, Daigneault I, Hébert M. Lessons learned from child sexual abuse research: prevalence, outcomes, and preventive strategies. Child Adolesc Psychiatry Ment Health 2013;7:22.

40. Kirby D. The impact of schools and school programs upon adolescent sexual behavior. J Sex Res 2002;39:27-33. 